\title{
Perinatal risk factors for developmental dysplasia of the hip
}

\author{
Annabelle Chan, Kieran A McCaul, Peter J Cundy, Eric A Haan, Rosemary Byron-Scott
}

Pregnancy Outcome

Unit,

A Chan

Health Statistics Unit, KA McCaul

Epidemiology Branch, South Australian Health Commission, PO Box 6, Rundle Mall, Adelaide, South Australia 5000

Department of Orthopaedic Surgery, PJ Cundy

South Australian Birth Defects Register,

Department of

Medical Genetics,

Women's and

Children's Hospital,

Adelaide

EA Haan

Rosemary Byron-Scott

Correspondence to: Dr Annabelle Chan.

Accepted 2 January 1997

\begin{abstract}
Aims-To identify perinatal risk factors for developmental dysplasia of the hip (DDH) and define the risk for each factor. Methods-In this case control study, using logistic regression analysis, all 1127 cases of isolated DDH live born in South Australia in 1986-93 and notified to the South Australian Birth Defects Register were included; controls comprised 150130 live births in South Australia during the same period without any notified congenital abnormalities.

Results-Breech presentation, oligohydramnios, female sex and primiparity were confirmed as risk factors for DDH. Significant findings were an increased risk for vaginal delivery over caesarean section for breech presentation (as well as an increased risk for emergency section over elective section), high birthweight $(\geqslant 4000$ g), postmaturity and older maternal age; multiple births and preterm births had a reduced risk. There was no increased risk for caesarean section in the absence of breech presentation. For breech presentation, the risk of DDH was estimated to be at least $\mathbf{2 . 7 \%}$ for girls and $\mathbf{0 . 8 \%}$ for boys; a combination of factors increased the risk. Conclusions-It is suggested that the risk factors identified be used as indications for repeat screening at 6 weeks of age and whenever possible in infancy. Other indications are family history and associated abnormalities.
\end{abstract}

(Arch Dis Child 1997;76:F94-F100)

Keywords: congenital hip dislocation; perinatal risk factors; screening; breech presentation.

Developmental dysplasia of the hip (DDH) embraces conditions of varying severity, from dislocated, dislocatable, or subluxatable hips to stable or clicky hips with radiological or ultrasound evidence of acetabular dysplasia. Early identification of affected infants is important for optimal outcome, as results of treatment become worse with delayed diagnosis after the neonatal period. ${ }^{1}$ Neonatal clinical screening programmes for the condition have been operative since the $1950 \mathrm{~s},{ }^{2}$ but have varying levels of sensitivity. Attempts to improve sensitivity have been based on the identification of infants at increased risk $^{3}$ and ancillary procedures such as ultrasound scanning, which may identify dysplastic hips that are clinically normal. ${ }^{13}$ Prevalence of the clinical condition has been reported to vary from 0.8 to 1.6 per
1000 births in populations not screened neonatally, but with high rates of 10 to 100 per 1000 births among ethnic communities, where infants are traditionally cradled or clothed with their hips extended and adducted; in screened populations, rates of 2.5 to 20 per 1000 births have been reported, but reach 40-90 per 1000 births in some communities. ${ }^{4}$ Differences in reported prevalence may be due to genetic differences and differences in clinical skills and methods used in detection as well as definition of the condition.

DDH has been associated with other "congenital postural deformities" $"$ such as sternomastoid torticollis, scoliosis, talipes, genu recurvatum, Potter's or compression facies (associated with oligohydramnios) and plagiocephaly. It has been suggested since Hippocratic times that these result from mechanical factors during later fetal life, altering the form of previously normally formed parts. This is supported by the rarity of the conditions in fetuses before 20 weeks of gestation. ${ }^{5} \mathrm{DDH}$ has also been associated with severe abnormalities such as meningomyelocoele, arthrogryposis, and muscular dystrophy, ${ }^{5}$ when it is classified as pathological, teratological, or paralytic dislocation.

Family studies ${ }^{6-11}$ have provided evidence that there is a genetic predisposition to DDH based on polygenic-multifactorial inheritance. These have shown a much higher concordance of the condition in monozygotic compared with dizygotic twins, and a significantly higher prevalence of DDH among siblings (4.3-14.0\%) and parents $(1.6-2.3 \%)$ of probands than would be expected from the population prevalence. Of environmental factors, breech presentation, with a prevalence of $11 \%$ to $50 \%$ in $\mathrm{DDH}^{679-16}$ has been considered the most important since the 19th century; female $\operatorname{sex}^{2} 910141517$ and primiparity ${ }^{911} 131517$ have been consistently associated with it. Postmaturity, ${ }^{13}{ }^{14} 16$ and, in single studies, upper social class, ${ }^{7}$ and miscarriage in the previous pregnancy ${ }^{18}$ have also been associated with it. There has been no consistent finding regarding month or season of birth, ${ }^{2}$ maternal age, ${ }^{911} 1417$ or birthweight. ${ }^{2} 101113141617$

The aim of the present study was to identify perinatal risk factors for DDH by linking cases with the perinatal data routinely collected on each birth in South Australia, to identify an "at risk" group of children and contribute to understanding of the aetiology of the condition.

\section{Methods}

South Australia has a population of 1.46 million people and about 20000 births every 
year. Since 1981, details of mother and baby for births occurring in the State have been routinely provided on a perinatal data collection form by midwives for the South Australian Health Commission's Pregnancy Outcome Unit, for the purpose of monitoring perinatal trends. This has been provided under legislation drawn up in 1986. The data comprise more than $99.5 \%$ of all births and include: sociodemographic details and information on previous pregnancies; medical and obstetric complications; presentation and method of delivery; birthweight; gestation; congenital abnormalities; and outcome up to 28 days of age. The notifications of congenital abnormalities identified at birth are complemented by notifications up to the child's fifth birthday to the South Australian Birth Defects Register from hospitals, special investigation and treatment centres, and practitioners dealing with children. The Register collates the statistics and reported a prevalence of DDH of 7.4 per 1000 births in South Australia for 1986-93. ${ }^{19}$

The present study was undertaken using the 1127 live born cases of DDH in 1986-93, including two multiple births, from which cases with major associated abnormalities had been excluded (as they may have other aetiologies, such as chromosomal abnormalities). All 164 live born cases of isolated $\mathrm{DDH}$ in one year (1991) which had been notified to the Register had been validated (as having dislocated/ dislocatable/subluxatable hips/acetabular dysplasia) by an orthopaedic surgeon for an earlier study. ${ }^{20}$ This earlier study identified 42 other cases of isolated DDH born in that year in South Australia by contacting all clinicians who might have been involved in identification and treatment. Thus $80 \%$ of DDH cases in 1991 had been notified to the Register and this included a larger proportion of the more severe cases. This study also showed that the perinatal risk factors identified were the same for the more severe category (dislocated and dislocatable hips) and the less severe category (subluxatable and acetabular dysplasia). This finding supported the use of all types of cases as one clinical entity in the current study. It is also assumed that diagnoses of $\mathrm{DDH}$ in the Register for the remaining years are also accurate. All 150130 live births without any notified congenital abnormalities in 1986-93 were used as controls, and odds ratios were calculated using EpiInfo ${ }^{21}$ for mother's age, race, country of birth, region of residence, parity, specific medical conditions, obstetric complications listed in the data set, and oligohydramnios, presentation and method of delivery, month of birth, birthweight, gestation, sex of baby and plurality. This study had $80 \%$ power to detect a twofold difference at the $5 \%$ level for variables with $1.0 \%$ prevalence among controls.

Variables with crude odds ratios (OR) showing significance $(\mathrm{P}<0.05)$ or borderline significance $(0.10>\mathrm{P} \geq 0.05)$ in association with $\mathrm{DDH}$ were entered into an unconditional logistic regression analysis using SPSS for Windows ${ }^{22}$ to determine which were independently associated after adjusting for confounding from the other variables included. All models were examined for goodness of fit, multicollinearity (using SAS/STAT ${ }^{23}$ ) and interaction among variables. Adjusted odds ratios (95\% confidence limits) were obtained for the variables in the final models by taking the exponentials of the respective regression coefficients $( \pm 1.96 \times$ standard error).

The coefficients obtained from logistic regression permitted the calculation of the probability of being a case, in this study the probability of having DDH, for each of the South Australian live births. The formula used for calculating the probability was:

$$
\mathrm{p}=\frac{\exp \left(\sum_{i} \alpha+\beta_{i} x_{i}\right)}{1+\exp \left(\sum_{i} \alpha+\beta_{i} x_{i}\right)}
$$

where $\alpha$ is the regression constant and the $\beta i$ are the regression coefficients. ${ }^{24}$ Furthermore, population attributable fractions (PAF) were calculated for possibly modifiable risk factors using the formula:

$$
\mathrm{PAF}=\frac{\mathrm{P}(\mathrm{OR}-1)}{\mathrm{P}(\mathrm{OR}-1)+1} \times 100
$$

where $\mathrm{P}=$ prevalence of the factor in the population (from the perinatal data collection for 1986-93).

\section{Results}

The variables found to be associated with DDH $(P<0.10)$ in univariate analysis (crude OR) were maternal age, region of residence, parity, oligohydramnios, presentation and method of delivery, baby's sex, birthweight, gestation and plurality. The adjusted OR for multiple births was $0.06(0.01,0.22)$ showing a $94 \%$ reduction in risk for multiple births compared with singletons. However, collinearity was found between plurality and birthweight, and all 4091 multiple births were then excluded from the analyses which are presented in table 1 for singleton births alone.

Logistic regression analysis using singleton live births showed that the following were independent risk factors for $\mathrm{DDH}$, in order of strength of association (adjusted OR) (table 1).

(1) Breech presentation: this considerably increased the risk compared with non-breech presentation; on the other hand, caesarean section in the absence of breech presentation was not associated with an increased risk compared with vaginal delivery, $\mathrm{OR}$ $1.10(0.92,1.31)$;

(a) Vaginal or caesarean delivery: the risk was significantly higher for vaginally delivered breech births, OR 17.15 (12.79, 22.99), than for breech births delivered by caesarean section, OR 10.03 (8.58,11.72).

(b) Emergency or elective caesarean delivery: the risk was higher for emergency section usually performed after the onset of labour, OR 13.19 (10.67,16.29), than for elective section performed as a planned procedure before the onset of labour, OR 7.56 (6.27, 9.12). (There were 116 cases, 1905 controls for emergency and 141 cases, and 2853 controls for elective caesarean, giving 
crude ORs of 10.53 and 8.54, respectively.)

(2) Oligohydramnios: this increased the risk nearly four times, OR 3.97 (1.69, 9.35).

(3) Female sex: the risk was also increased nearly four times for females compared with males, OR $3.94(3.41,4.56)$.

(4) High birthweight: an increasing risk was seen with increasing birthweight. Babies of 4000-4499 $\mathrm{g}$ had an OR of 1.55 (1.26, 1.91) and those of $4500 \mathrm{~g}$ and above had an OR of 2.67 (1.81, 3.94). Low birthweight $(<2500 \mathrm{~g})$ was protective.

(5) Primiparity: there was an increasing risk with decreasing parity, with primiparous women having more than twice the risk, OR $2.19(1.83,2.62)$, of women of parity 2 or more.

(6) Older maternal age: there was increasing risk with increasing age, with mothers of 30 to 34 years having an OR of 1.71 (1.26, 2.32) compared with mothers of under 20 years.

(7) Postmaturity: there was an increasing risk with increasing gestation above term, with postmature babies ( $\geq 42$ weeks of gestation) having an OR of $1.48(1.02,2.13)$ while gestation up to 38 weeks was protective.

(8) Metropolitan region of residence: metropoli$\tan$, OR $1.45(1.23,1.69)$ and outer metropolitan residents, OR 1.86 (1.41, 2.46), had an increased risk compared with country residents.

Interaction occurred between sex and presentation and method of delivery. Therefore, separate models were used for each sex. The model for females (table 2) which included most DDH babies $(n=882)$, was remarkably similar to the model which included all babies. The same risk factors emerged, with similar levels of risk. In the model for males (table 3), on the other hand, the much reduced number of DDH cases $(n=243)$ and controls resulted in no significant increased risk for ages 30 years and above, parity 1 , breech delivery over caesarean delivery for breech presentation, any region of residence, oligohydramnios, birthweight 4000-4499 g, or late gestation, and less consistency in the trends noted for maternal age and birthweight.

The probability of being a case for any variable or combination of variables is presented in tables 4 (females) and 5 (males), where the probability for the reference infant (maternal age $<20$ and parity 2 or more, country resident, non-breech presentation, absence of oligohydramnios, birthweight 3000-3499 g and gestation 40 weeks) is $0.3 \%$ for females and $0.05 \%$ for males. The population attributable fractions (PAF) for possibly modifiable risk factors-breech presentation delivered vaginally, breech presentation delivered by caesar-

Table 1 Adjusted and crude odds ratios of factors associated with DDH in South Australian singleton live births (1986-93)

\begin{tabular}{|c|c|c|c|c|c|}
\hline \multirow[b]{2}{*}{ Variables } & \multicolumn{2}{|c|}{ No of subjects } & \multirow{2}{*}{$\begin{array}{l}\text { Crude OR } \\
\text { OR }(95 \% C I)\end{array}$} & \multirow{2}{*}{$\begin{array}{l}\text { Adjusted } O R^{\star} \\
\text { OR }(95 \% C I)\end{array}$} & \multirow{2}{*}{$\begin{array}{l}\text { Coefficients }(\beta) \text { in } \\
\text { logisitc regression } \\
\text { analysis }\end{array}$} \\
\hline & $\begin{array}{l}\text { Cases } \\
(n=1125)\end{array}$ & $\begin{array}{l}\text { Controls } \\
(n=146041)\end{array}$ & & & \\
\hline \multicolumn{6}{|l|}{ Mother's age (yrs): } \\
\hline$<20$ & 52 & 8725 & 1.00 & 1.00 & 0.0000 \\
\hline $20-24$ & 228 & 32169 & $1.19(0.87,1.63)$ & $1.30(0.96,1.76)$ & 0.2618 \\
\hline $25-29$ & 431 & 5572 & $1.30(0.97,1.76)$ & $1.46(1.09,1.96)$ & 0.3798 \\
\hline $30-34$ & 313 & 36967 & $1.42(1.05,1.93)$ & $1.71(1.26,2.32)$ & 0.5360 \\
\hline $35+$ & 101 & 12608 & $1.34(0.95,1.91)$ & $1.72(1.22,2.44)$ & 0.5440 \\
\hline \multicolumn{6}{|l|}{ Parity: } \\
\hline 0 & 624 & 58976 & $2.13(1.79,2.52)$ & $2.19(1.83,2.62)$ & 0.7825 \\
\hline 1 & 322 & 51089 & $1.27(1.05,1.53)$ & $1.29(1.07,1.56)$ & 0.2553 \\
\hline $2+$ & 179 & 35976 & 1.00 & 1.00 & 0.0000 \\
\hline \multicolumn{6}{|l|}{ Presentation and delivery: } \\
\hline Non-breech presentation & 813 & 140533 & 1.00 & 1.00 & 0.0000 \\
\hline Breech, caesarean delivery & 257 & 4758 & $9.34(8.07,10.80)$ & $10.03(8.58,11.72)$ & 2.3058 \\
\hline Breech, breech delivery & 55 & 750 & $12.68(9.46,16.95)$ & $17.15(12.79,22.99)$ & 2.8420 \\
\hline \multicolumn{6}{|l|}{ Baby's sex: } \\
\hline Female & 882 & 70602 & $3.88(3.36,4.48)$ & $3.94(3.41,4.56)$ & 1.3717 \\
\hline Male & 243 & 75439 & 1.00 & 1.00 & 0.0000 \\
\hline \multicolumn{6}{|l|}{ Region of residence: } \\
\hline Metropolitan & 858 & 102487 & $1.56(1.33,1.82)$ & $1.45(1.23,1.69)$ & 0.3690 \\
\hline Outer metropolitan & 69 & 6751 & $1.90(1.43,2.52)$ & $1.86(1.41,2.46)$ & 0.6199 \\
\hline Country & 198 & 36803 & 1.00 & 1.00 & 0.0000 \\
\hline \multicolumn{6}{|l|}{ Oligohydramnios: } \\
\hline Present & 6 & 209 & $3.74(1.50,8.73)$ & $3.97(1.69,9.35)$ & 1.3790 \\
\hline Absent & 1119 & 145832 & 1.00 & 1.00 & 0.0000 \\
\hline \multicolumn{6}{|l|}{ Birthweight (g): } \\
\hline$<2000$ & 6 & 2260 & $0.33(0.13,0.77)$ & $0.30(0.12,0.77)$ & -1.1971 \\
\hline $2000-2499$ & 17 & 4468 & $0.48(0.28,0.79)$ & $0.52(0.31,0.88)$ & -0.6469 \\
\hline $2500-2999$ & 174 & 21782 & $1.00(0.84,1.20)$ & $0.90(0.75,1.08)$ & -0.1066 \\
\hline $3000-3499$ & 440 & 55214 & 1.00 & 1.00 & 0.0000 \\
\hline $3500-3999$ & 335 & 45627 & $0.92(0.80,1.07)$ & $1.12(0.97,1.30)$ & 0.1133 \\
\hline $4000-4499$ & 124 & 14318 & $1.09(0.89,1.33)$ & $1.55(1.26,1.91)$ & 0.4367 \\
\hline $4500+$ & 29 & 2372 & $1.53(1.03,2.27)$ & $2.67(1.81,3.94)$ & 0.9819 \\
\hline \multicolumn{6}{|l|}{ Gestation (weeks): } \\
\hline$<37$ & 24 & 7428 & $0.44(0.28,0.67)$ & $0.42(0.25,0.69)$ & -0.8703 \\
\hline 37 & 31 & 5992 & $0.70(0.48,1.02)$ & $0.59(0.40,0.86)$ & -0.5299 \\
\hline 38 & 136 & 17993 & $1.02(0.84,1.24)$ & $0.80(0.66,0.98)$ & -0.2214 \\
\hline 39 & 224 & 25133 & $1.20(1.03,1.41)$ & $0.90(0.76,1.06)$ & -0.1035 \\
\hline 40 & 517 & 69833 & 1.00 & 1.00 & 0.0000 \\
\hline 41 & 161 & 16862 & $1.29(1.08,1.55)$ & $1.26(1.05,1.51)$ & 0.2311 \\
\hline $42+$ & 32 & 2800 & $1.54(1.06,2.24)$ & $1.48(1.02,2.13)$ & 0.3891 \\
\hline Constant & & & & & -7.2099 \\
\hline
\end{tabular}

${ }^{\star}$ Logistic regression analysis. 
ean section and for postmaturity-are presented in table 6 .

\section{Discussion}

The perinatal data used in this study have already been shown to have a very high level of reliability for variables which were risk factors in the study - mother's age and parity, presentation and method of delivery, sex, plurality, birthweight and gestation, with $\kappa$ values of 0.85 to 1.00 when compared with hospital case records. ${ }^{25}$ Kappa values of greater than 0.75 indicate excellent agreement beyond chance. ${ }^{26}$ The reliability of these perinatal data and the demonstration in the study of cases of DDH in 1991 of the uniformity of risk factors for both milder and more severe categories of DDH supported the use of data for 1986-93.

The trends in the odds ratios suggestive of a dose-response relation in age, parity, birthweight and gestation, provide strong support for the associations noted. The results confirm those of other studies in relation to breech presentation, female sex, oligohydramnios and primiparity as risk factors, but there are some new findings or risk factors that have had little previous support. These are: breech delivery increasing the risk for breech presentation; high birthweight; older maternal age; postmaturity; and metropolitan residence. Interestingly, in a Western Australian study which used Statewide perinatal data and a univariate analysis, ${ }^{14}$ the increasing risks with increasing age and gestation were also noted.
It has been suggested that risk factors operate through increasing pressure on the fetus or through decreasing resistance to dislocation. ${ }^{4}$ In primiparity, the high tone of the previously undistended uterine wall would restrict the fetus, as would high birthweight or the reduction of amniotic fluid in oligohydramnios and postmaturity; it is not clear how an increase in maternal age results in suboptimal fetal accommodation. An association between older maternal age and amniocentesis was explored by including amniocentesis in the logistic regression analysis, but it did not emerge as a risk factor (OR 0.62 (95\% CI 0.30, 1.28)). This study found that preterm birth (<37 weeks of gestation) and multiple birth both reduced the risk of DDH (by $58 \%$ and $94 \%$, respectively). The lower risk in early gestation may be related to the greater mobility of the smaller fetus in a relatively larger volume of amniotic fluid. Multiple births are of lower birthweight than singletons and showed collinearity with birthweight in the logistic regression analysis. The prevalence of $\mathrm{DDH}$ among multiple births in this study was 0.5 per 1000 live births compared with 7.7 for singletons.

It has been suggested that high concentrations of relaxin in DDH may contribute to connective tissue and hip joint laxity. This facilitates hip displacement, which interferes with the leg folding mechanism, resulting in breech malposition (with hips flexed and knees extended). ${ }^{56} \mathrm{~A}$ recent study showed no signifi-

Table 2 Adjusted and crude odds ratio of factors associated with DDH in South Australian Singleton female live births (1986-93)

\begin{tabular}{|c|c|c|c|c|c|}
\hline \multirow[b]{2}{*}{ Variables } & \multicolumn{2}{|c|}{ No of subjects } & \multirow{2}{*}{$\begin{array}{l}\text { Crude OR } \\
\text { OR }(95 \% C I)\end{array}$} & \multirow{2}{*}{$\begin{array}{l}\text { Adjusted } O R^{\star} \\
\text { OR }(95 \% C I)\end{array}$} & \multirow{2}{*}{$\begin{array}{l}\text { Coefficients }(\beta) \text { in } \\
\text { logisitc regression } \\
\text { analysis }\end{array}$} \\
\hline & $\begin{array}{l}\text { Cases } \\
(n=882)\end{array}$ & $\begin{array}{l}\text { Controls } \\
(n=70602)\end{array}$ & & & \\
\hline \multicolumn{6}{|l|}{ Mother's age (yrs): } \\
\hline$<20$ & 44 & 4160 & 1.00 & 1.00 & 0.0000 \\
\hline $20-24$ & 181 & 15694 & $1.09(0.77,1.54)$ & $1.21(0.86,1.69)$ & 0.1888 \\
\hline $25-29$ & 314 & 26703 & $1.11(0.80,1.55)$ & $1.25(0.90,1.72)$ & 0.2196 \\
\hline $30-34$ & 262 & 18044 & $1.37(0.99,1.92)$ & $1.68(1.21,2.35)$ & 0.5196 \\
\hline $35+$ & 81 & 6001 & $1.28(0.87,1.88)$ & $1.63(1.11,2.40)$ & 0.4907 \\
\hline \multicolumn{6}{|l|}{ Parity: } \\
\hline 0 & 482 & 28382 & $2.06(1.70,2.50)$ & $2.17(1.77,2.65)$ & 0.7744 \\
\hline 1 & 256 & 24736 & $1.26(1.02,1.55)$ & $1.30(1.06,1.61)$ & 0.2657 \\
\hline $2+$ & 144 & 17484 & 1.00 & 1.00 & 0.0000 \\
\hline \multicolumn{6}{|l|}{ Presentation and delivery: } \\
\hline Non-breech presentation & 655 & 67683 & 1.00 & 1.00 & 0.0000 \\
\hline Breech, caesarean delivery & 185 & 2507 & $7.63(6.42,9.05)$ & $8.65(7.21,10.38)$ & 2.1576 \\
\hline Breech, breech delivery & 42 & 412 & $10.53(7.49,14.76)$ & $15.10(10.79,21.13)$ & 2.7147 \\
\hline \multicolumn{6}{|l|}{ Region of residence: } \\
\hline Metropolitan & 672 & 49687 & $1.58(1.32,1.90)$ & $1.48(1.23,1.77)$ & 0.3901 \\
\hline Outer metropolitan & 59 & 3222 & $2.15(1.57,2.93)$ & $2.12(1.56,2.89)$ & 0.7521 \\
\hline Country & 151 & 17693 & 1.00 & 1.00 & 0.0000 \\
\hline \multicolumn{6}{|l|}{ Oligohydramnios: } \\
\hline Present & 5 & 116 & $3.46(1.25,8.81)$ & $4.07(1.59,10.43)$ & 1.4030 \\
\hline Absent & 877 & 70486 & 1.00 & 1.00 & 0.0000 \\
\hline \multicolumn{6}{|l|}{ Birthweight (g): } \\
\hline$<2000$ & 6 & 1099 & $0.44(0.18,1.02)$ & $0.36(0.14,0.95)$ & -1.0147 \\
\hline $2000-2499$ & 14 & 2480 & $0.46(0.26,0.80)$ & $0.51(0.28,0.90)$ & -0.6819 \\
\hline $2500-2999$ & 142 & 12573 & $0.91(0.75,1.11)$ & $0.88(0.71,1.08)$ & -0.1320 \\
\hline $3000-3499$ & 356 & 28751 & 1.00 & 1.00 & 0.0000 \\
\hline $3500-3999$ & 255 & 19901 & $1.03(0.88,1.22)$ & $1.13(0.95,1.33)$ & 0.1185 \\
\hline $4000-4499$ & 89 & 5115 & $1.41(1.10,1.79)$ & $1.60(1.26,2.04)$ & 0.4694 \\
\hline $4500+$ & 20 & 683 & $2.36(1.46,3.80)$ & $2.95(1.85,4.70)$ & 1.0801 \\
\hline \multicolumn{6}{|l|}{ Gestation (weeks): } \\
\hline$<37$ & 21 & 3441 & $0.51(0.32,0.80)$ & $0.47(0.27,1.23)$ & -0.7533 \\
\hline 37 & 23 & 2829 & $0.68(0.43,1.05)$ & $0.58(0.38,0.91)$ & -0.5392 \\
\hline 38 & 102 & 8782 & $0.97(0.77,1.21)$ & $0.78(0.62,0.98)$ & -0.2484 \\
\hline 39 & 173 & 12320 & $1.17(0.97,1.40)$ & $0.89(0.74,1.08)$ & -0.1115 \\
\hline 40 & 410 & 34077 & 1.00 & 1.00 & 0.0000 \\
\hline 41 & 128 & 7873 & $1.35(1.10,1.66)$ & $1.28(1.04,1.56)$ & 0.2433 \\
\hline $42+$ & 25 & 1280 & $1.62(1.06,2.48)$ & $1.49(0.98,2.25)$ & 0.3958 \\
\hline Constant & & & & & -5.7437 \\
\hline
\end{tabular}

${ }^{\star}$ Logistic regression analysis. 
cant difference in mean relaxin concentration between cord bloods of a group of 24 babies with $\mathrm{DDH}$ and a group of normal babies matched by gestation and sex; however, the authors suggest that relaxin receptor expression of the developing fetal hip joint needs to be explored. ${ }^{27}$

Earlier studies have not explored the association between caesarean delivery and $\mathrm{DDH}$ in the absence of breech presentation, yet it has been assumed that caesarean section is a risk factor. ${ }^{13}$ They have also not explored the difference between elective and emergency caesarean section nor used a multivariate analysis on all available data: conflicting results concerning the prevalence of $\mathrm{DDH}$ among vaginally delivered compared with caesarean delivered breech babies have been reported, ${ }^{12}{ }^{16}{ }^{28}$ some studies being limited by small numbers.

Table 3 Adjusted and crude odds ratios of factors associated with DDH in South Australian singleton male live births (1986-93)

\begin{tabular}{|c|c|c|c|c|c|}
\hline \multirow[b]{2}{*}{ Variables } & \multicolumn{2}{|c|}{ No of Subjects } & \multirow{2}{*}{$\begin{array}{l}\text { Crude OR } \\
\text { OR }(95 \% C I)\end{array}$} & \multirow{2}{*}{$\begin{array}{l}\text { Adjusted } O R^{\star} \\
\text { OR }(95 \% C I)\end{array}$} & \multirow{2}{*}{$\begin{array}{l}\text { Coefficients }(\beta) \text { in } \\
\text { logisitc regression } \\
\text { analysis }\end{array}$} \\
\hline & $\begin{array}{l}\text { Cases } \\
(n=243)\end{array}$ & $\begin{array}{l}\text { Controls } \\
(n=75439)\end{array}$ & & & \\
\hline \multicolumn{6}{|l|}{ Mother's age (yrs): } \\
\hline$<20$ & 8 & 4565 & 1.00 & 1.00 & 0.0000 \\
\hline $20-24$ & 47 & 16475 & $1.63(0.74,3.73)$ & $1.74(0.82,3.71)$ & 0.5545 \\
\hline $25-29$ & 117 & 28869 & $2.31(1.09,5.10)$ & $2.58(1.25,5.34)$ & 0.9492 \\
\hline $30-34$ & 51 & 18923 & $1.54(0.70,3.50)$ & $1.75(0.82,3.75)$ & 0.5614 \\
\hline $35+$ & 20 & 6607 & $1.73(0.72,4.27)$ & $2.13(0.92,4.95)$ & 0.7568 \\
\hline \multicolumn{6}{|l|}{ Parity: } \\
\hline 0 & 142 & 30594 & $2.45(1.67,3.62)$ & $2.25(1.52,3.33)$ & 0.8100 \\
\hline 1 & 66 & 26353 & $1.32(0.86,2.04)$ & $1.24(0.82,1.88)$ & 0.2147 \\
\hline $2+$ & 35 & 18492 & 1.00 & 1.00 & 0.0000 \\
\hline \multicolumn{6}{|l|}{ Presentation and delivery: } \\
\hline Non-breech presentation & 158 & 72850 & 1.00 & 1.00 & 0.0000 \\
\hline Breech, caesarean delivery & 72 & 2251 & $14.75(11.02,19.72)$ & $16.35(12.06,22.16)$ & 2.7942 \\
\hline Breech, breech delivery & 13 & 338 & $17.73(9.53,32.36)$ & $28.72(15.91,51.85)$ & 3.3576 \\
\hline \multicolumn{6}{|l|}{ Region of residence: } \\
\hline Metropolitan & 186 & 52800 & $1.43(1.03,2.00)$ & $1.35(0.97,1.87)$ & 0.2984 \\
\hline Outer metropolitan & 10 & 3529 & $1.15(0.55,2.36)$ & $1.07(0.54,2.12)$ & 0.0641 \\
\hline Country & 47 & 19110 & 1.00 & 1.00 & 0.0000 \\
\hline \multicolumn{6}{|l|}{ Oligohydramnios: } \\
\hline Present & 1 & 93 & $3.35(0.46,24.11)$ & $3.47(0.44,27.49)$ & 1.2435 \\
\hline Absent & 242 & 75346 & 1.00 & 1.00 & 0.0000 \\
\hline \multicolumn{6}{|l|}{ Birthweight (g): } \\
\hline$<2000$ & 0 & 1161 & $0.00(0.00,1.31)$ & $0.02(0,82.96)$ & -4.0938 \\
\hline $2000-2499$ & 3 & 1988 & $0.48(0.12,1.56)$ & $0.69(0.43,2.35)$ & -0.3775 \\
\hline $2500-2999$ & 32 & 9209 & $1.09(0.71,1.67)$ & $1.09(0.71,1.66)$ & 0.0865 \\
\hline $3000-3499$ & 84 & 26463 & 1.00 & 1.00 & 0.0000 \\
\hline $3500-3999$ & 80 & 25726 & $0.98(0.71,1.35)$ & $1.10(0.80,1.51)$ & 0.0953 \\
\hline $4000-4499$ & 35 & 9203 & $1.20(0.79,1.81)$ & $1.45(0.96,2.18)$ & 0.3688 \\
\hline $4500+$ & 9 & 1689 & $1.68(0.79,3.45)$ & $2.44(1.21,4.96)$ & 0.8940 \\
\hline \multicolumn{6}{|l|}{ Gestation (weeks): } \\
\hline$<37$ & 3 & 3987 & $0.25(0.06,0.82)$ & $0.24(0.07,0.83)$ & -1.4105 \\
\hline 37 & 8 & 3163 & $0.85(0.38,1.79)$ & $0.56(0.26,1.20)$ & -0.5754 \\
\hline 38 & 34 & 9211 & $1.23(0.82,1.84)$ & $0.86(0.57,1.30)$ & -0.1471 \\
\hline 39 & 51 & 12813 & $1.33(0.94,1.88)$ & $0.95(0.67,1.35)$ & -0.0497 \\
\hline 40 & 107 & 35756 & 1.00 & 1.00 & 0.0000 \\
\hline 41 & 33 & 8989 & $1.23(0.81,1.84)$ & $1.21(0.81,1.80)$ & 0.1873 \\
\hline $42+$ & 7 & 1520 & $1.54(0.66,3.43)$ & $1.41(0.65,3.06)$ & 0.3408 \\
\hline Constant & & & & & -7.6060 \\
\hline
\end{tabular}

${ }^{\star}$ Logistic regression analysis.

Table 4 Risk of DDH: female baby

\begin{tabular}{|c|c|c|c|c|c|c|c|}
\hline \multirow[b]{2}{*}{ Risk factors } & \multicolumn{2}{|c|}{ Breech presentation } & \multirow[b]{2}{*}{ Oligohydramnios } & \multirow{2}{*}{$\begin{array}{l}\text { High } \\
\text { birthweight } \\
(\geq 4500 \mathrm{~g})\end{array}$} & \multirow[b]{2}{*}{ Primipara } & \multirow[b]{2}{*}{ Age 35+ } & \multirow[b]{2}{*}{ Post-maturity } \\
\hline & $\begin{array}{l}\text { Caesarean } \\
\text { delivery }\end{array}$ & $\begin{array}{l}\text { Vaginal } \\
\text { delivery }\end{array}$ & & & & & \\
\hline No other risk factor & $2.7 \%$ & $4.6 \%$ & $1.3 \%$ & $0.9 \%$ & $0.7 \%$ & $0.5 \%$ & $0.5 \%$ \\
\hline +Oligohydramnios & $10.1 \%$ & $16.4 \%$ & & $3.7 \%$ & $2.7 \%$ & $2.1 \%$ & $1.9 \%$ \\
\hline +High birthweight & $7.5 \%$ & $12.5 \%$ & & & $2.0 \%$ & $1.5 \%$ & $1.4 \%$ \\
\hline +Primipara & $5.7 \%$ & $9.5 \%$ & & & & $1.1 \%$ & $1.0 \%$ \\
\hline +Age $35+$ & $4.3 \%$ & $7.3 \%$ & & & & & $0.8 \%$ \\
\hline +Postmaturity & $4.0 \%$ & $6.7 \%$ & & & & & \\
\hline +Oligohydramnios & & & & & & & \\
\hline $\begin{array}{l}\text { +high birthweight } \\
+ \text { Oligohydramnios }\end{array}$ & $24.9 \%$ & $36.7 \%$ & & & $7.7 \%$ & $5.9 \%$ & $5.4 \%$ \\
\hline $\begin{aligned} & \text { +primipara } \\
+ & \text { High birthweight }\end{aligned}$ & $19.6 \%$ & $29.9 \%$ & & & & $4.4 \%$ & $4.0 \%$ \\
\hline +primipara & $15.0 \%$ & $23.6 \%$ & & & & $3.2 \%$ & $3.0 \%$ \\
\hline $\begin{array}{l}\text { +Age } 35++ \text { postmaturity } \\
+ \text { Oligohydramnios +age }\end{array}$ & $6.3 \%$ & $10.5 \%$ & $3.1 \%$ & $2.2 \%$ & $1.7 \%$ & & \\
\hline $\begin{aligned} & 35+ \\
+ & \text { Oligohydramnios }\end{aligned}$ & $15.5 \%$ & $24.3 \%$ & & & & & \\
\hline $\begin{aligned} & + \text { postmaturity } \\
+ & \text { High birthweight }+ \text { age }\end{aligned}$ & $14.3 \%$ & $22.6 \%$ & & & & & \\
\hline $\begin{aligned} & 35+ \\
+ & \text { High birthweight }\end{aligned}$ & $11.8 \%$ & $18.9 \%$ & & & & & \\
\hline +postmaturity & $10.8 \%$ & $17.5 \%$ & & & & & \\
\hline +Primipara +age 35+ & $8.9 \%$ & $14.6 \%$ & & & & & \\
\hline +Primipara +postmaturity & $8.2 \%$ & $13.5 \%$ & & & & & \\
\hline
\end{tabular}


Table 5 Risk of DDH: male baby

\begin{tabular}{|c|c|c|c|c|c|c|c|}
\hline \multirow[b]{2}{*}{ Risk factors } & \multicolumn{2}{|c|}{ Breech presentation } & \multirow[b]{2}{*}{ Oligohydramnios } & \multirow{2}{*}{$\begin{array}{l}\text { High } \\
\text { birthweight } \\
(\geq 4500 g)\end{array}$} & \multirow[b]{2}{*}{ Primipara } & \multirow[b]{2}{*}{ Age 35+ } & \multirow[b]{2}{*}{ Post-maturity } \\
\hline & $\begin{array}{l}\text { Caesarean } \\
\text { delivery }\end{array}$ & $\begin{array}{l}\text { Vaginal } \\
\text { delivery }\end{array}$ & & & & & \\
\hline No other risk factor & $0.8 \%$ & $1.4 \%$ & $0.2 \%$ & $0.1 \%$ & $0.1 \%$ & $0.1 \%$ & $0.1 \%$ \\
\hline +Oliogohydramnios & $2.7 \%$ & $4.7 \%$ & & $0.4 \%$ & $0.4 \%$ & $0.4 \%$ & $0.2 \%$ \\
\hline +High birthweight & $1.9 \%$ & $3.4 \%$ & & & $0.3 \%$ & $0.3 \%$ & $0.2 \%$ \\
\hline +Primipara & $1.8 \%$ & $3.1 \%$ & & & & $0.2 \%$ & $0.2 \%$ \\
\hline +Age $35+$ & $1.7 \%$ & $3.0 \%$ & & & & & $0.1 \%$ \\
\hline +Postmaturity & $1.1 \%$ & $2.0 \%$ & & & & & \\
\hline +Oligohydramnios & & & & & & & \\
\hline $\begin{array}{l}\text { +high birthweight } \\
\text { +Oligohydramnios }\end{array}$ & $6.5 \%$ & $10.8 \%$ & & & $0.9 \%$ & $0.9 \%$ & $0.6 \%$ \\
\hline $\begin{aligned} &+ \text { primipara } \\
&+ \text { High birthweight }\end{aligned}$ & $6.0 \%$ & $10.0 \%$ & & & & $0.8 \%$ & $0.5 \%$ \\
\hline $\begin{array}{l}\quad+\text { primipara } \\
+ \text { Age } 35+\end{array}$ & $4.3 \%$ & $7.3 \%$ & & & & $0.6 \%$ & $0.4 \%$ \\
\hline $\begin{array}{l}\text { +postmaturity } \\
+ \text { Oligohydramnios }\end{array}$ & $2.4 \%$ & $4.1 \%$ & $0.5 \%$ & $0.4 \%$ & $0.3 \%$ & & \\
\hline $\begin{array}{l}\text { +age } 35+ \\
+ \text { Oligohydramnios }\end{array}$ & $5.7 \%$ & $9.6 \%$ & & & & & \\
\hline $\begin{array}{c}\text { +postmaturity } \\
+ \text { High birthweight }\end{array}$ & $3.8 \%$ & $6.5 \%$ & & & & & \\
\hline $\begin{aligned} &+ \text { age } 35+ \\
&+ \text { High birthweight }\end{aligned}$ & $4.1 \%$ & $6.9 \%$ & & & & & \\
\hline $\begin{array}{r}\text { +postmaturity } \\
+ \text { Primipara +age }\end{array}$ & $2.7 \%$ & $4.7 \%$ & & & & & \\
\hline $\begin{aligned} & 35+ \\
+ & \text { Primipara, }\end{aligned}$ & $3.8 \%$ & $6.4 \%$ & & & & & \\
\hline+ postmaturity & $2.5 \%$ & $4.3 \%$ & & & & & \\
\hline
\end{tabular}

This study has shown no increased risk for $\mathrm{DDH}$ for caesarean delivery in the absence of breech presentation. Interestingly, $85 \%$ of singleton breech presentations were delivered by caesarean section. Breech presentation imposes at least a sevenfold increased risk (that of breech delivered by elective caesarean section), but the risk for breech delivered vaginally is considerably greater (17 times that for nonbreech presentation). The risk for breech delivery by emergency caesarean section is intermediate, suggesting that external forces during parturition affect hip joint stability. It could be argued that it is only the truly dislocated or dislocatable hip which is affected in this way by delivery method, and that the breech position for several months' gestation produces the acetabular dysplasia by a gentle moulding process. The association of type of breech presentation-breech with extended legs, with an increased risk for breech delivery-could not be evaluated, as examination of a sample of 47 case records of mothers of breech presentation DDH babies showed that in many cases the reason for delivery by caesarean section was not related to the type of breech presentation but to factors such as maternal age, inadequate pelvis, large baby, previous caesarean section, failure to progress, fetal distress and maternal request. Frequently, the type of breech presentation was also not noted in the case records. As the prevalence of breech delivered vaginally is only $0.9 \%$ among live births in South Australia, using population

Table 6 Population attributable fraction (PAF) for possibly modifiable risk factors

\begin{tabular}{llll}
\hline Risk factor & $\begin{array}{l}\text { Population } \\
\text { prevalence }\end{array}$ & Adjusted OR & PAF \\
\hline $\begin{array}{l}\text { Breech presentation delivered vaginally } \\
\text { Breech presentation delivered by caesarean (those } \\
\quad \text { currently delivered vaginally only) }\end{array}$ & 0.009 & 17.15 & $12.7 \%$ \\
$\begin{array}{l}\text { Breech presentation currently delivered by } \\
\quad \text { caesarean }\end{array}$ & 0.009 & 10.03 & $7.5 \%$ \\
Postmaturity & 0.039 & 10.03 & $26.0 \%$ \\
\hline
\end{tabular}

attributable fractions (table 6), the estimated reduction in prevalence of DDH as a result of delivering these breech presentations by caesarean section would be only $5.2 \%$ (12.7$7.5 \%)$. In any case, in the absence of other specific benefits of caesarean delivery ${ }^{29}$ and the fact that DDH is readily treatable, such a recommendation would be untenable. Another factor to consider is whether external cephalic version of a breech presentation baby at 38 weeks of gestation would result in a reduction in risk of $\mathrm{DDH}$. If this risk were eliminated, then the potential reduction in DDH prevalence from converting all breech to non-breech presentations (which cannot be achieved) would be $38.7 \%(12.7 \%+26.0 \%)$ (table 6$)$, which is quite substantial. The identification of these risk factors supports the hypothesis that, although a genetic predisposition to $\mathrm{DDH}$ exists, DDH is probably a deformation occurring in later gestation in utero which may be aggravated by the passage through the birth canal in breech presentation. These findings need to be replicated in other studies. While boys have a much lower risk of $\mathrm{DDH}$ than girls (3.2 vs 12.3 per 1000 singleton live births), and also a lower risk of breech presentation $(3.5 \%$ vs $4.4 \%$ being breech presentations in this study), the level of increased risk of DDH for boys with breech presentation was almost twice that for girls (OR 16.35 vs 8.65 for caesarean delivery) (tables 2 and 3 ).

The finding of an association between metropolitan or outer metropolitan residence and $\mathrm{DDH}$ is consistent with the higher prevalence among babies born in metropolitan hospitals in Western Australia. ${ }^{14}$ This may be related to better reporting in metropolitan regions: the prevalence of total birth defects is higher in these regions, but there is no increased prevalence for sentinel defects (a group of severe defects readily identifiable at 
birth and used internationally for monitoring purposes)..$^{19}$

We had no information on family history, which is believed to exercise its influence either through generalised joint laxity (more common in neonatally diagnosed cases), or the development of acetabular dysplasia (more common in late diagnosed cases, in which environmental factors have a smaller role). ${ }^{7} 10^{14}$

The neonatal screening programme in South Australia, using the Ortolani and Barlow tests, as in many developed countries, is a part of the routine physical examination of the neonate by a medical practitioner shortly after birth. We recommend further screening in infancy of those with normal tests who have identified risk factors. Examinations on certain occasions entail little additional costs, while considerable expense would be imposed by a special visit to a paediatrician or an orthopaedic surgeon or an ultrasound examination for all babies. These occasions include the following:

(1) before discharge from hospital after birth (as additional cases may be detected) ${ }^{30}$

(2) when babies are reviewed at about 6 weeks of age by paediatricians, obstetricians, and midwives; and

(3) the visits to the Child and Youth Health (or well baby) clinic.

It would therefore be reasonable to target an educational programme to all medical practitioners, particularly obstetricians and paediatricians, and child health nurses and midwives. We recommend that this programme include information on $\mathrm{DDH}$, the importance of early detection, the clinical method of screening, the risk factors, and the need for repeated screening (to increase sensitivity ${ }^{31}$ ) for "at risk" groups until the child is walking, and for referral to an orthopaedic surgeon when DDH is suspected. Perinatal information is included in the personal health record of the baby which is provided by each obstetric unit on discharge after birth, and this record could be used to advise parents of "at risk" births to facilitate programme implementation.

The principal "at risk" groups would be those identified in the study. If we use a risk estimate of $1 \%$ for DDH derived from the logistic regression analysis as a basis for repeated screening, tables 4 and 5 suggest that the baby should be a breech presentation (risk at least $2.7 \%$ for girls and $0.8 \%$ for boys) to be included. This would apply to $4-5 \%$ of South Australian babies. Combinations of risk factors, a family history in first degree relative/s, and the associated abnormalities mentioned would warrant inclusion of other babies.

We gratefully acknowledge the role of South Australian midwives, neonatal nurses, and medical practitioners in their provision of perinatal data. We also express our sincere thanks to professor Jeffrey Robinson, associate professor Alastair MacLennan, and Dr Paul Duggan of the University of Adelaide Department of Obstetrics and Gynaecology for their helpful advice, to Mr Jon Tgetgel, Department of Orthopaedic Surgery, for validating DDH cases born in 1991, and to Mrs Rosemary
Keane and Mrs Maureen Fisher of the Pregnancy Outcome Unit for their assistance with data retrieval and typing.

1 Cole WG. Screening for congenital dislocation of the hip in Australia. F Paediatr Child Health 1991;27:143-6.

2 Heikkila E. Congenital dislocation of the hip in Finland. Acta Orthop Scand 1984;55:125-9.

3 Special report. Screening for the detection of congenital dislocation of the hip. Arch Dis Child 1986;61:921-6.

4 Leck I. An epidemiological assessment of neonatal screening for dislocation of the hip. $\mathcal{F} R$ Coll Physicians Lond 1986;20:56-62.

5 Dunn PM. Congenital postural deformities. Br Med Bull 1976;32:71-6.

6 Wilkinson JA. Prime factors in the etiology of congenital dislocation of the hip. F Bone foint Surg 1963;45B:268-83.

7 Wynne-Davies R. Acetabular dysplasia and familial joint laxity: two aetiological factors in congenital dislocation of the hip. A review of 589 patients and their families. F Bone foint Surg 1970;52B:704-16.

8 Czeizel A, Szentpetery J, Tusnady G, Vizkelety T. Two family studies on congenital dislocation of the hip after early orthopaedic screening in Hungary. F Med Genet 1975;11: 125-30.

9 Woolf CM, Koehn JH, Coleman SS. Congenital hip disease in Utah: the influence of genetic and non-genetic factors. Am f Human Genet 1968;20:430-9.

10 Bjerkreim I, van der Hagen CB. Congenital dislocation of the hip joint in Norway. V. Evaluation of genetic and environmental factors. Clin Genet 1974;5:433-48.

11 Record RG, Edwards JH. Environmental influences related to the aetiology of congenital dislocation of the hip. $\mathrm{Br} F$ Prev Soc Med 1958;12:8-22.

12 Luterkort M, Perrson PH, Polberger S, Bjerre I. Hip joint instability in breech pregnancy. Acta Paediatr Scand 1986;75:860-3.

13 Cyvin KB. Congenital dislocation of the hip. Acta Paediatr Scand 1977;263(Suppl): 1-67.

14 Bower C, Stanley FJ, Kricker A. Congenital dislocation of the hip in Western Australia. A comparison of neonatally and postneonatally diagnosed cases. Clin Orthop 1987;224:37-44.

15 Gunther A, Smith SJ, Maynard PV, Beaver MW, Chilvers CED. A case control study of congenital hip dislocation. Soc Public Health 1993;107:9-18.

16 Hinderaker T, Doltveit AK, Irgens LM, Uden A, Reikeras O. The impact of intrauterine factors on neonatal hip instability. Acta Orthop Scand 1994;65:239-42.

17 Robinson GW. Birth characteristics of children with congenital dislocation of the hip. Am $\mathcal{F}$ Epidemiol 1968;87:275-84.

18 Paz JE, Otano L, Gadow EC, Castilla EE. Previous miscarriage and stillbirth as risk factors for other unfavourable outcomes in the next pregnancy. Br $\mathcal{f}$ Obstet Gynaecol 1992; 99: 808-12.

19 South Australian Birth Defects Register. Annual Report 1993. Women's and Children's Hospital, Adelaide: January 1995 .

20 Yiv BC, Saidin R, Cundy PJ, Tgetgel JD, Aguilar J, McCaul KA, et al. Developmental dysplasia of the hip in South KA, et al. Developmental dysplasia of the hip in South Child Health (in press).

21 Dean AG, Dean JA, Burton AH, Dicker RC. Epi Info Version 5.01: a word processing, database and statistics program for epidemiology on microcomputers. USD, Stone Mountain, Georgia, USA, 1990.

22 SPSS. SPSS for Windows Base System User's Guide, Release 6.0. SPSS Inc., Chicago, Illinois: 1990.

23 SAS Institute Inc. SAS/STAT User's Guide, Release 6.03 Edition. Cary, NC: SAS Institute Inc., 1988.

24 Hosmer DW Jr, Lemeshow S. Applied logistic regression. New York: John Wiley \& Sons, Inc. 1989: 25-6.

25 Jonas $\mathrm{O}$, Scott J, Chan A, Macharper T, Lister J. A validation study of the 1986 South Australian perinatal data collection study of the 1986 South Austrahan perinatal data collection form. Pregnancy Outcome Un

26 Fleiss JL. Statistical Methods for Rates and Proportions. 2nd edn. New York: John Wiley \& Sons, 1981: 212-36.

27 Borthwick GM, Borthwick AC, Grant P, MacLennan AH. Relaxin levels in the human: an indicator of target, storage and production sites. In: MacLennan AH, Tregear GW, Bryant-Greenwood GD, eds. Progress in relaxin research. Proceedings of the Second International Congress on the Hormone Relaxin, Adelaide, South Australia. USA: Global Publications Services, 1995:251-60.

28 Clausen I, Nielsen KT. Breech position, delivery route and congenital hip dislocation. Acta Obstet Gynaecol Scand 1988;67:595-7.

29 Hannah M, Hannah W. Caesarean section or vaginal birth for breech presentation at term. BMF 1996;312:1433.

30 Dunn PM, Evans RE, Thearle MJ, Griffiths HED, Witherow PJ. Congenital dislocation of the hip: early and late diagnosis and management compared. Arch Dis Child 1985;60:407-14

31 Bialik V, Fishman J, Katzir J, Zeller M. Clinical assessment of hip instability in the newborn by an orthopaedic surgeon and a paediatrician. $\mathcal{F}$ Pediatr Orthop 1986;6:703-5. 